\title{
Paradigms in Action
}

\author{
Paradigmas em ação
}

PAULO PIROZELLI (iD ${ }^{a}$

\begin{abstract}
The concept of "paradigm" became widely known with Thomas Kuhn's book The Structure of Scientific Revolutions. From there on, paradigms started being employed in the most diverse fields and situations. Curiously, though, the popularity of the term went hand in hand with an enormous vagueness in its application: numerous meanings were attributed to this concept and different things were claimed to be paradigms. The main reason for the lack of agreement regarding the notion and the use of paradigm was the absence of a detailed description and analysis of a concrete paradigm in Kuhn's book-especially, one coupled with a discussion that could contrast paradigms to other epistemic objects, such as "theories." The aim of this article is to fill this gap. First, I briefly examine the notion of paradigm, stressing its core meaning as that of "exemplar." Next, I analyze a specific case in economics, indicating the features that make it a paradigm: (i) the fact that it is an example not reducible to an axiomatizable theory, and (ii) that this example is constitutive of normal science.
\end{abstract}

Keywords: Thomas Kuhn. Paradigm. History of Economic Thought.

\section{Resumo}

O conceito de "paradigma" tornou-se amplamente conhecido com o livro de Thomas Kuhn, A estrutura das revoluções científicas. Logo, paradigmas começaram a ser empregados nos mais diversos campos. Curiosamente, a popularidade do termo sempre caminhou junto com uma enorme imprecisão em sua aplicação: diversos significados foram atribuídos a esse conceito e diferentes coisas foram reivindicadas como constituindo paradigmas. A principal razão para a falta de concordância em relação à noção e ao uso de paradigma foi a falta de uma descrição e análise detalhadas de um paradigma concreto no livro de Kuhn - especialmente, uma que

a Universidade de Federal de Santa Catarina (UFSC), Florianópolis, SC, Brasil. Doutor em Filosofia, e-mail: paulopirozelli@gmail.com 
estivesse associado a uma discussão que contrastasse paradigmas com outros objetos epistêmicos, como teorias. O objetivo deste artigo é preencher essa lacuna. Primeiro, examino brevemente a noção de paradigma, enfatizando seu significado central como "exemplar". Em seguida, analiso um caso em economia, indicando as características que o tornam um paradigma: (i) o fato de que é um exemplo não redutível a uma teoria axiomatizável, e (ii) que é constitutivo da ciência normal.

Palavras-chave: Thomas Kuhn. Paradigma. História do Pensamento Econômico.

\section{Introduction}

It is hard to think of a concept in the philosophy of science that has been more widely analyzed, employed, criticized, and trivialized than that of a "paradigm." Since Thomas Kuhn first used the term in his book The Structure of Scientific Revolutions (SSR, 1962), paradigms have gained a life of their own, surpassing the boundaries of philosophy itself. ${ }^{1}$

Historians of various disciplines soon began to employ this concept in their own analyses. Many books and articles were written with the aim of identifying paradigms in fields not previously described by Kuhn, such as psychology, education, and economics (e.g., ARGYROUS, 1992; MANGEE, 2015). On the philosophical side, discussions centered on the nature of these objects, as well as their actual applicability to the understanding of the history of science (see, for example, the essays in MUSGRAVE \& LAKATOS, 1970). Scientists themselves also began to talk about paradigms, either as a way of highlighting the originality of new theoretical and experimental approaches, or as part of ideological strategies in the struggle for institutionalization, or as a way of guaranteeing social support from the scientific community and from the general public.

\footnotetext{
${ }^{1}$ The notion of a "paradigm" had already appeared in other authors (see CEDERBAUM, 1983, for a historical appraisal). Two interesting precursors are Wittgenstein (1953) and Toulmin (1960). But it is the Kuhnian version that became the best known. Abbot (2016) gives an overview of the impact of the term through the use of citational analysis. For a short history of SSR's impact and the importance of paradigms to it, see Hacking (2016).
} 
The popularity of the term, measured by the frequency of usage, can be seen from a chart extracted from Google N-grams above (Figure 1). From the 1960s on, there was an exponential growth in the occurrence of "paradigm."

Figure 1 - Frequency of the word "paradigm", according to Google NGram Viewer (2019)

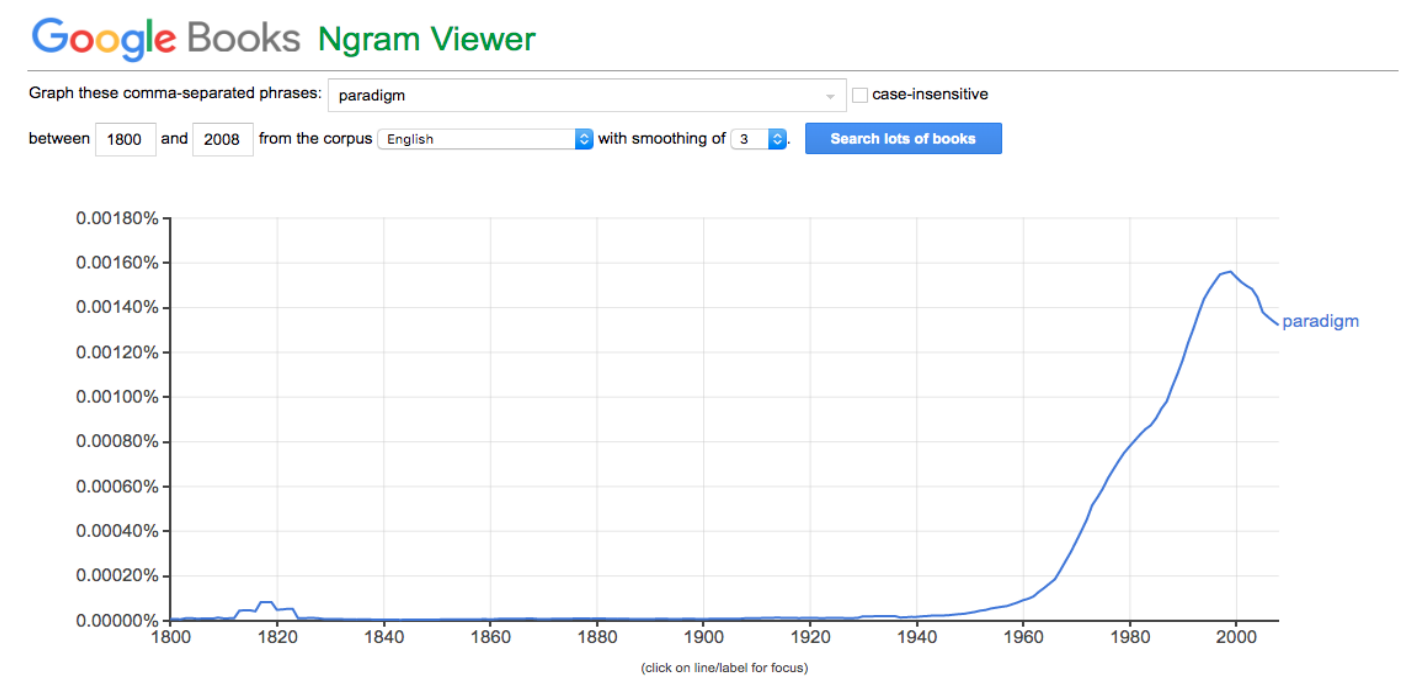

Two main factors explain the explosion of the use of "paradigm" in the literature of so many fields and with such different goals. The first of these has to do with the descriptive and explanatory power of Kuhn's theory. SSR presented a model of scientific development that allowed someone to interpret historical data through a concise but eloquent scheme, in which a regular pattern of closely connected steps succeeded. And within this framework, paradigms played a central role.

The second cause for the popularity of the concept, unfortunately, has to do with the ambiguity of the term in SSR. In a certain sense, this is a hackneyed criticism. Soon after the book was published, for instance, Masterman (1970) was listing no less than 21 different senses of the term. It is not fair, though, to claim that Kuhn never cared to explain what he understood by that word, or that he was not very successful in his intent. Even in the first edition of SSR, it is possible to identify the different meanings of paradigm and Kuhn's use of them (maybe with a small dose of hindsight).

Also, in his post-SSR work, especially (1970a) and (1970b), Kuhn spent a good deal of time explaining what paradigms were. Thus, we may ask, what makes 
paradigms so prone to misinterpretation and gives rise to different kinds of interpretations and applications?

I believe there is a serious gap in Kuhn's explanation of paradigms. It is a shortcoming that may sound very prosaic, when compared to discussions about the use of paradigms in historical explanations or about the scope of incommensurability, but it is one which is relevant to our understanding of paradigms nonetheless. The problem is that Kuhn does not examine any detailed example of a paradigm in his philosophical writings. ${ }^{2}$

My impression is that much of the flexibility that the term has acquired through time, beyond the boundaries of the philosophy of science itself, is due to the lack of a precise illustration of a paradigm in his writings. Sure, SSR identifies numerous paradigms throughout history and even points out some of their key features. However, Kuhn never shows in practice how a paradigm differs from theories, conceptual schemes, or simple assumptions. He does not analyze any case in detail, showing why it needs to be described as a paradigm and not as something else. ${ }^{3} \mathrm{I}$ believe this is why people tend to see paradigms everywhere, and this is also why they tend to disagree so much about what cases constitute paradigmatic changes.

The purpose of this article is, thus, quite simple. First, I want to present a theoretical definition of paradigm, according to SSR and (1970b). A paradigm is defined as the solution to a problem that serves as a model for other solutions. The following section analyzes a detailed example of a paradigm in economics and shows

\footnotetext{
${ }^{2}$ In his two case studies in the history of science, The Copernican Revolution (1957) and Black-Body Theory and the Quantum Discontinuity, 1894-1912 (1987), Kuhn gives concrete and lengthy examples of paradigms. Nonetheless, he tended to separate his case studies in the history of science from his philosophical work (his study on Copernican was also written before he elaborated the notion of paradigm). Furthermore, these studies suffer from a disadvantage: they are complex and involve considerable technical discussions. Recently, Shan (2020) has tried to develop the notion of "exemplar" and apply it to the history of genetics. My goal here is not to develop this concept any further, though, but simply to recover its meaning from Kuhn's work and illustrate this with an example of the history of economic thought.

${ }^{3}$ Curiously, the best presentation of a paradigm is maybe Toulmin's (1960). However, his example is in the field of optics, which is almost a branch of mathematics. The example I will present in economics involves, I believe, more of the features that are characteristic of the natural sciences.
} 
how it functions within normal science. Finally, I discuss some features of paradigms that differentiate them from more traditional concepts in the philosophy of science.

With this, I hope that the nature of paradigms can become clearer, making their role within the Kuhnian project more intelligible and displaying better their usefulness as a methodological tool in the history of science. Kuhn saw the paradigm as central to his model of scientific development. It would be interesting to give it a second chance.

\section{What are Paradigms?}

SSR presents a considerable variety of uses of "paradigm," but it is in later writings, especially in the Postscript to the second edition of the book (1970b) that the concept is best explained. ${ }^{4}$ There, Kuhn tries to pinpoint the precise meaning of the term amidst the polysemic multitude that characterized its original presentation. According to him, the concept of paradigm encompasses two main notions: those of a "disciplinary matrix" and a "shared example." By "disciplinary matrix," Kuhn meant the whole set of commitments shared by a community of experts. Its main components would be symbolic generalizations, heuristics, values, and exemplars. The second meaning of paradigm identified by Kuhn was that of "exemplars," one of the components of the disciplinary matrix (a paradigm in the first sense) ${ }^{5}$.

Kuhn regarded the notion of "exemplar" as being the most fundamental sense of paradigm, the one he originally had in mind. The idea of exemplar can be best understood by considering what Kuhn wanted to contrast them with, namely "scientific theories." According to a then-popular school of thought, the syntactic or

\footnotetext{
${ }^{4}$ A good description of how Kuhn came to paradigms and the transformations the concept suffered throughout his writings, see Wray (2011, ch. 3).

${ }^{5}$ Both meanings of the term can be found, in a slightly obscured way, in SSR. One of the reasons for this conflation is related to the book's genesis. According to Hoyningen-Huene (2015), chapter five of SSR, which emphasizes the nature of paradigms as exemplary, was a late addition to the text. It was placed there in the end of the writing process, after the first draft, when it became clear to Kuhn that paradigms do not provide strict rules for research, but simply guide the activity of scientists through model solutions. Kuhn, however, did not completely solve this internal tension in SSR. Chapter 4 shows this older view, in which paradigms are seen as providing some sort of shared rules for normal science.
} 
axiomatic view, science was characterized by the use of theories. These were understood as axiomatizable "set of sentences expressed in terms of a specific vocabulary" (HEMPEL, 1958, p. 182-83). Philosophers were then supposed to rationally reconstruct the scientific theories in a meta-mathematical language in order to make explicit the postulates and rules that connected them to observations. The sentences that constituted theories would be of three types: theoretical (the axioms and theorems), observational (descriptions of experiential findings), and correspondence (tying together the first two classes of sentences). Theoretical sentences made use of theoretical and logical terms; observational sentences used logical and observational ones; and correspondence sentences, since they connected both theoretical and observational sentences, needed to employ all three kinds of concepts.

Kuhn thought of paradigms as an alternative to the emphasis on scientific theories in philosophical analysis. For him, instead of theories, practitioners in a certain field acquired scientific knowledge by means of "concrete puzzle-solutions" (1970b, p. 174)—“examples which include law, theory, application, and instrumentation together" (1962, p. 11). Scientific activity was based on these problem-solutions, not on theories.

Two arguments are offered by Kuhn to defend the prominence of exemplars over theories: one is descriptive, the other, normative. First, he claims that describing scientific activity as based on theories is an inaccurate description of how scientists acquire and produce knowledge. Scientists are not taught strict definitions of theoretical concepts. Nor is most of their learning characterized by the transmission of explicit theorems derived from axioms. Additionally, scientists do not learn rules of correspondence (or something from which these rules could be extracted). Generally, it is enough for scientists to have a general and operative understanding of concepts like "energy" or "species," and then to have a good understanding of what kind of situations are under the paradigm's scope and constitute, for example, a case of "forced motion," as well as to have an idea on how to solve new problems based on the previous solutions, as a case of "evolution." It is that knowledge, in great part implicit and non-propositional, that defines scientific knowledge. Theories and explicit rules are a fundamental, but restricted, part of the scientific enterprise. 
It could be objected, though, that the fact that scientists do not use scientific theories does not imply that their knowledge could not be reconstructed as such. Kuhn offers a normative argument to rebut this line of reasoning. According to him, reducing scientific knowledge to theories is inevitably to misrepresent it. Paradigms are not just a practical substitute for real theoretical knowledge-a pedagogical deficiency that could be circumvented by a rational reconstruction. While the scope of the applicability of a theory is previously delimited, paradigmatic solutions possess an essentially open nature.

Such an openness derives from their function as models. The exemplary nature of a solution is not a quality that some problem-solutions have and others do not, but rather something that a problem-solution acquires by being treated as such by scientists. Broadly, being a model means that these problem-solution have two special features.

First, a paradigm delimits the problems that "can be assumed to have solutions" (1962, p. 37). Only problems that are seen as similar to it are considered as being scientifically legitimate and, hence, as having a possible solution. In the second place, these paradigms restrict scientists' courses of action by limiting "both the nature of acceptable solutions and the steps by which they are to be obtained" (1962, p. 38). They determine the general structure a problem-solution should have. In sum, paradigms define what situations can be considered as "solvable," while at the same time offering indications on how to provide such solutions. These "universally recognized scientific achievements" (1962, p. xlii) work, thus, as models for future research. They are exemplary standards that provide, within a scientific community, "the foundations for its further practice" (1962, p. 10).

Because they are not explicit sets of sentences, but models, paradigms can be used to solve new and unpredictable types of problems. A theory's range of application, on the contrary, is delimited in advance by its explicit theoretical sentences and correspondence rules. A paradigm, on the other hand, has an open scope of applicability. It is the task of scientists to discover what situations resemble a standard problem and see if analogous solutions can be found. Newton's laws would be perhaps the most perfect example, in Kuhn's view, of the paradigms "from which spring particular coherent traditions of scientific research” (1962, p. 11). 


\section{A Paradigm in Economics}

According to Kuhn, paradigms can be identified by inspecting the technical literature of a field (1970b, sec. 1). Of special relevance for this are textbooks, which are especially designed for conveying in a systematic and comprehensive way established paradigms to new practitioners.

In its modern form, textbooks have been a standard tool in the natural sciences at least since the nineteenth century (BENSAUDE-VINCENT, 2006). Textbooks are currently employed in most undergraduate (and often, graduate) courses in the sciences. Although each book may hold different perspectives on the field, disagreements among them tend to be small, particularly when dealing with more basic areas and well-settled paradigms. Despite offering different perspectives, textbooks aim to introduce students to the same basic tools.

Except for its more humanistic disciplines, in which attention to original textual sources is still encouraged, the same dynamics occurs in much of economics. In order to see what paradigms are and how they work, I selected a very popular textbook in introductory economics, Gregory Mankiw's Principles of Economics (2017). Just to put some numbers on that, the book had sold, according the author's homepage (MANKIW, 2019), over two million copies and has been translated into twenty languages. There is no better document that could be used to examine the paradigms students are supposed to learn in introductory economic courses.

In the fourth chapter of the book, Mankiw explains how the prices of goods in an economy are determined. What makes a product have a specific value? The answer is given by a partial equilibrium theory. ${ }^{6}$ First, the supply of a product is seen as depending on its price. The higher the market value, the more people will offer it. Demand, by contrast, is also dependent on price, but has the opposite direction. People avoid buying expensive products. These ideas can be seen as part of an economic theory: they contain information regarding a person's behavior.

\footnotetext{
${ }^{6}$ Which, despite the name, I believe, is actually a paradigm. 
Next, the theory gains a mathematical outline. Supply and demand are presented as mathematical functions in which price is the dependent variable and quantity (supplied or demanded) is the independent variable. In both cases

$$
f(p)=q
$$

in which $q$ is the quantity of a good and $p$ its price. Depending on the level of the course and the approach, the remarks regarding the agent's behavior can gain more precise specifications. Demand is defined as a negative monotonic function, that is, whenever the price increases, the quantity offered falls:

$$
\frac{d f_{\text {demand }}(p)}{d p}<0
$$

Similarly, supply is defined as a positive monotonic function; that is, whenever the price increases, the quantity offered also increases:

$$
\frac{d f_{\text {supply }}(p)}{d p}>0
$$

Treating the supply and demand of a good as mathematical functions that involve the same variables is computationally convenient. This allows us to conceive the price of a good as the solution of a system of equations. Mathematically, it is expressed as

$$
\left\{f_{d}(p)=q f_{s}(p)=q\right.
$$

which can be reduced to the following equality:

$$
f_{d}=f_{s}
$$

A causal explanation provides the other part of the story, making the notion of equilibrium more intuitive (even though an equilibrium state is defined 
mathematically and not causally). If there is too much of a good, suppliers will have to either lower their production costs or leave the market. The process only ends when the supplied quantity of a good is equal to what is demanded.

The causal relation is also explained the other way around, from prices to quantity. An increase in prices generates a decrease in supply. This shows that the mathematical conception has a priority over causal explanations, since independent and dependent variables are often treated as interchangeable (they are established simultaneously).

Economic textbooks, however, prefer to work with graphs, rather than pure mathematical deductions, because visualizations "provide a powerful way of finding and interpreting patterns" (MANKIW, 2017, p. 37). Furthermore, these tools are relatively familiar to students in their daily life, therefore dispensing with advanced mathematical and conceptual resources as their first approach to the material.

The use of graphs also helps the students to perceive the essential elements in the problem-solution and understand that this is an idealized problem. It does not matter, for example, what is the curve's specific shape, but only its general tendency — demand falls with price, and supply, increases.

Hence, the mathematical problem of price determination can be graphically represented as in Figure 2:

Figure 2 - MANKIW (2017, p. 77)

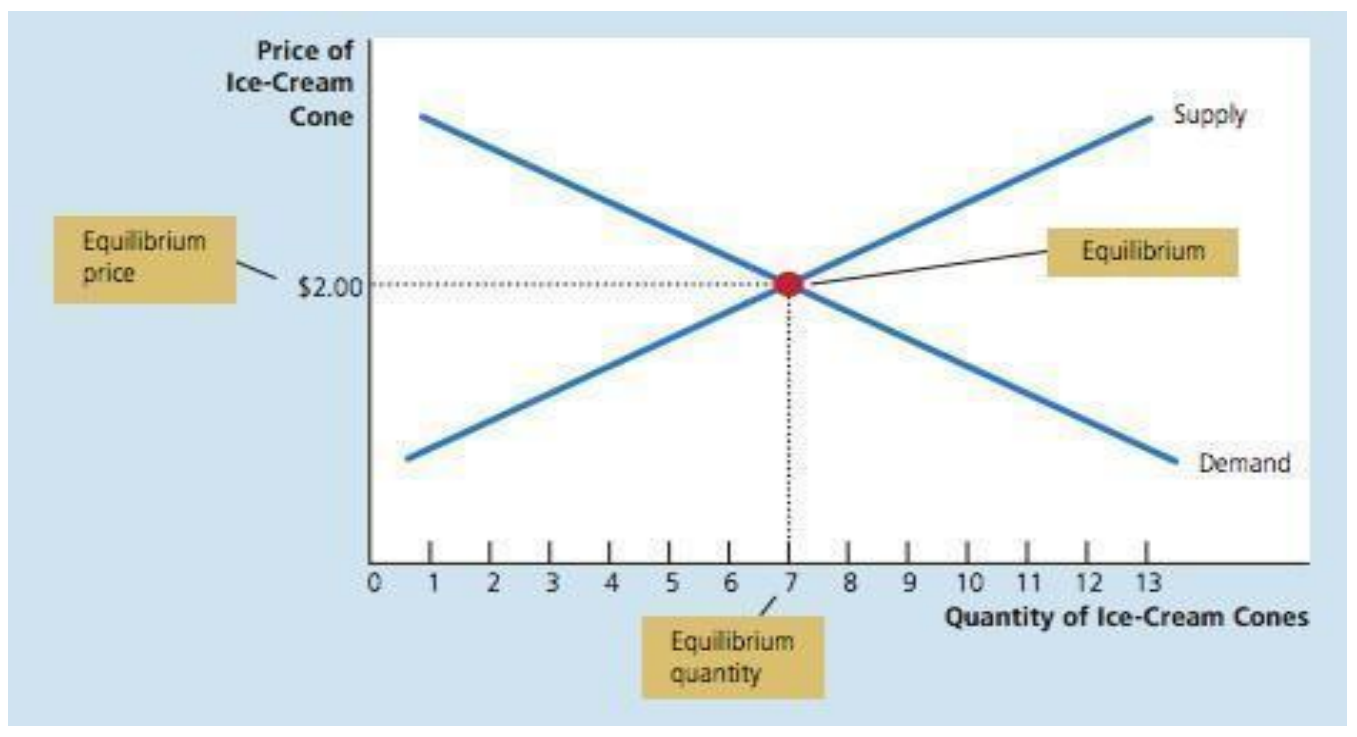

Note: ${ }^{\circledR} 2018$ South-Western, a part of Cengage, Inc. Reproduced by permission. 
This is how undergraduate students usually learn how to determine the price of a good in an economy. This is an example of a paradigm. However, in order to understand why it is said to have a paradigmatic nature, let us look at another question taught in economics courses, the establishment of interest rates.

For this, I am going to analyze another very popular textbook, employed in more advanced (but still mostly undergraduate) macroeconomics courses, Olivier Blanchard's Macroeconomics (2017). The problem of what determines the interest rate in an economy is a fundamental topic in such courses, being a core component of any analysis of economic policies.

The reason why this topic is usually presented in later courses is that students already need to master some prior economic ideas (particularly, how the prices of goods in the economy are established). Solving the new problem requires considering it through a particular lens. First, the students need to see this as a problem similar to the establishment of the price of a common good in an economy. Money, for instance, is presented as a good. Next, the interest rate is defined as nothing more than the price of money: on the one hand, it indicates how much people are willing to pay to borrow it, and on the other, how much people demand to lend it. Consequently, the supply and demand of money in the economy are seen as functions of the interest rate.

The second step is to find an answer that is similar to the one that was offered for the basic case of a common good. The solution, however, is not simply an instance of a general solution, but a conceptual extension of the solution of the old problem to the new one. ${ }^{7}$ The dissimilarity, in this case, is related to the supply function. The amount of money available in the economy does not work as in other kinds of products. Money is different from other goods in the economy because it is under the monopoly of central banks (at least, if we consider currency only).

\footnotetext{
${ }^{7}$ The fact that the formation of interest rate may be thought as an instance of a more general price formation law, maybe even a natural one, is a distortion caused by the development of normal science. It is exactly because this problem was not seen at the time simply as an instance of the general problem of price formation that the solution to it required so much time (and why it is usually presented in a different and more advanced course of macroeconomics).
} 
"Suppliers" of money cannot simply enter into the market as a response to an increase in the interest rate.

The supply of money is, therefore, the result of a political decision and for this reason it is indifferent to changes in price. As a consequence, the interest rate, established by the equality of supply and demand, does not vary with price either. It is, according to economic language, inelastic.

Mathematically, this can be put as:

$$
\left\{f_{d}(q)=p f_{s}(q)=z\right.
$$

in which $z$ is a constant. Solving this system of equations gives:

$$
p=z
$$

Graphically, this can be expressed as follows (Figure 3):

Figure 3 - BLANCHARD (2017, p. 72)

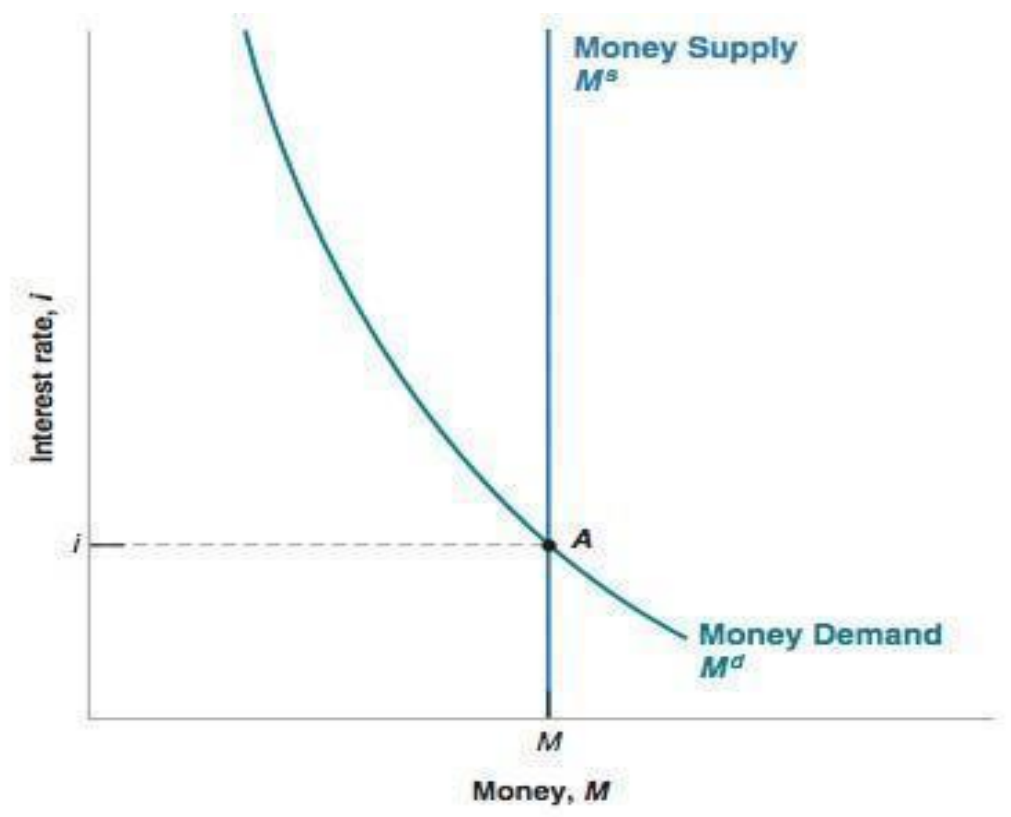

Note: (C2017. Reprinted by permission of Pearson Education, Inc., New York, New York.

The student of macroeconomics is supposed to understand how the interest rate in an economy is determined and the main forces settling it. By knowing that, 
the student can predict particular values for the interest rates when specific functions are given. Even more importantly, the student is now capable of thinking counterfactually about matters of economic policy_-if the central bank issues more money, for example, then the interest rate should fall.

\section{Paradigms as Exemplars}

Now we can answer the question of what makes our first example a paradigm. First of all, it is a concrete problem-solution, an answer to a particular problem. In this particular case, it dealt with how to find the price of a good in an economy and under what conditions this could be achieved.

Attached to this solution comes a number of explicit elements, especially regarding the economic behavior of agents. For example, demand for a good is seen as inversely proportional to its price. However, despite its explicit theoretical assumptions, two aspects make this problem-solution distinct from a theory.

For the one hand, it is less than a theory: it does not rigorously define the meaning of the terms it employs, does not necessarily explain how to measure or connect them to observations, does not state all knowledge involved in explicit sentences, and is not structured as a system of logical deduction. Moreover, it does not provide any criteria for determining which possible situations are similar to the exemplar. As De Regt (2017, p. 34) states, "the construction of models is not a matter of deduction but a complex process involving approximations and idealizations. There are no algorithms or formal principles that tell us how to get from the description of a real system to a suitable model." Reducing it to an axiomatizable set of sentences would imply considerable explanatory losses. A theory is not the way students learn how to find prices, and therefore it is not the knowledge they possess and use in their practice.

On the other hand, this problem-solution is also more than a theory. It implicitly or tacitly tells what a typical problem-situations is, how it relates to previous cases, and how to connect the relevant elements within a mathematical 
instrumental (e.g., the price of a good as the simultaneous solution to a system of equations with two functions).

A paradigm is also different from a theory because it is necessarily incomplete. Think, for example, about the supply and demand functions. Strictly speaking, they are not really functions. They are more like function schemes. Blanchard (2017, p. 72), for example, defines the demand for money in the following way:

$$
M^{d}=\$ Y L(i)^{-}
$$

in which $M^{d}$ denotes the demand for money, $\$ Y$ the nominal income and $L(i)^{-}$is a decreasing function of the interest rate $i$.

We are not told what kind of function $L(i)^{-}$is, except that it is decreasing. Is it linear, logarithmic, exponential, or does it have a different shape? Moreover, the function scheme does not say anything regarding other factors that not the interest rate and the nominal income which would affect $M^{d}$.

The paradigm must also be distinguished from a metaphor or a heuristic, even if it contains those elements to some degree. A metaphor is relatively unclear regarding the consequences that can be drawn from it. The analogical content of a paradigm, on the contrary, is very informative. Treating money as a good, for instance, implies seeing this situation as similar to a previous one (a regular good), bringing with it the basic features of a solution (e.g., the search for a solution in a system of equations).

Another essential aspect of a paradigm is its function as a model. The paradigm is a basic problem-solution that is envisaged as a prototypical case from which more complex solutions can be built. The case discussed above is a good example. First, there was a solution to a specific problem (even if it is of a general nature)- the establishment of prices in a market economy. Next, a new situation was treated as similar to the first one-the establishment of the interest rate. This, by turn, allows one to structure an analogous solution. It is this exemplary feature that generates a normal science tradition, making room for a series of more and more complex puzzles.

According to Kuhn, problems in normal science can be of three main types: "determination of significant fact, matching of facts with theory, and articulation of 
theory" (1962, p. 34). We can see the same kinds of problems being originated by our paradigm. Just to give a few examples: Determination of significant fact: what is the precise shape of the supply function? Matching of facts with theory: how to determine the price of a specific good in the economy? Articulation of theory: what happens if the supply or demand function is not linear? Is there an equilibrium state in a market with many goods?

\section{Conclusion}

"Paradigms" are certainly Kuhn's most fruitful and fascinating concept. Their widespread use, unfortunately, has come in great part intertwined with a serious misunderstanding. Here, I have tried to explain what paradigms are by giving a simple example in economics: the establishment of an equilibrium price.

Paradigms are generally understood as a set of broad propositional commitments. As I hope to have shown, their nature is, instead, that of an exemplary problem-solution. Thus, there are two main features that characterize a paradigm. In the first place, it is a concrete solution to a problem, involving all sorts of elements: generalizations, vocabulary, and mathematical tools, among other things. It is, in this sense, simultaneously more and less than a theory.

The second aspect that makes this a prototypical paradigm is that it serves as a model. Scientists learn how to see other situations as similarly problematic and, for this reason, to search for solutions that are analogous to it.

Seeing what paradigms really are, why Kuhn created them, and what phenomenon they describe, helps us to better understand his project. It also allows us to evaluate its accuracy and fruitfulness when applied to the history of science.

\section{References}

ABBOT, A. Structure as cited, structure as read. In: R. J. RICHARDS; L. DASTON. Kubn's Structure of Scientific Revolutions at Fifty: Reflections on a Science Classic. Chicago: Chicago University Press, p. 167-81, 2016. 
ARGYROUS, G. Kuhn's paradigms and neoclassical economics. Economics and Philosophy, v. 8, n. 2, p. 231-248, 1992.

BENSAUDE-VINCENT, B. Textbooks on the map of science studies. Science \& Education, v. 15, n. 7, p. 667-670, 2016.

BLANCHARD, O. Macroeconomics. $7^{\text {a }}$ ed., New York: Pearson, 2017.

CEDERBAUM, D. G. Paradigms. Stud. Hist. Phil Sci, v. 14, n. 3, p. 173-213, 1983.

DE REGT, H. W. Understanding Scientific Understanding. Oxford: Oxford University Press, 2017.

GOOGLE NGRAM VIEWER. 2019. Paradigm. Available at: https://books.google.com/ngrams. Accessed on: October 27th, 2019.

HACKING, I. Paradigms. In: R. J. RICHARDS; L. DASTON. Kubn's Structure of Scientific Revolutions at Fifty: Reflections on a Science Classic. Chicago: Chicago University Press, p. 96-115, 2016.

HEMPEL, C. G. The theoretician's dilemma: A study in the logic of theory construction. In: C. G. HEMPEL. Aspects of Scientific Explanation: And Other Essays in the Philosophy of Science. New York: The Free Press, p. 173-226, 1958.

HOYNINGEN-HUENE, P. Kuhn's development before and after structure. In: W. J. DEVLIN; A. BOKULICH. Kubn's Structure of Scientific Revolutions - 50 Years On. Springer, p. 185-95, 2015.

KUHN, T. S. The Copernican revolution: Planetary astronomy in the development of Western thought. Cambridge, MA: Harvard University Press, 1957.

KUHN, T. S. The Structure of Scientific Revolutions. $2^{a}$ ed., Chicago: University of Chicago Press, 2012. [1962]

KUHN, T. S. Logic of discovery or psychology of research? In: The Essential Tension: Selected Studies in Scientific Tradition and Change. Chicago: University of Chicago Press, 1977. [1970a]

KUHN, T. S. Postscript. In: The Structure of Scientific Revolutions. $2^{\mathrm{a}}$ ed., Chicago, University of Chicago Press, 2012. [1970b]

KUHN, T. S. Black-Body Theory and the Quantum Discontinuity, 1894-1912. Chicago, University of Chicago Press, 1987.

MANGEE, N. J. A Kuhnian perspective on asset pricing theory. Journal of Economic Methodology, v. 22, n. 1, p. 28-45, 2015.

MANKIW, G. N. Principles of microeconomics, $8^{a}$ ed. Cengage Learning, 2017.

MANKIW, G. N. Biography. Available at: https://scholar.harvard.edu/mankiw/biocv. Accessed on: October 27th, 2019.

MASTERMAN, M. The nature of a paradigm. In: A. MUSGRAVE; I. LAKATOS. Criticism and the Growth of Knowledge. Cambridge: Cambridge University Press, 1970. 
MUSGRAVE, A.; LAKATOS, I. Criticism and the Growth of Knowledge. Cambridge: Cambridge University Press, 1970.

SHAN, Y. “Kuhn’s 'wrong turning' and legacy today”. Synthese 197, 381-406, 2020.

TOULMIN, S. The Philosophy of Science: an Introduction. Harper Row, 1960.

WITTGENSTEIN, L. Philosophical Investigations. Basil, 2009. [1953]

WRAY, K. B. Kubn's Evolutionary Social Epistemology. Cambridge: Cambridge University Press, 2011.

WRAY, K. B. Kuhn and the history of science. In: M. FRICKER; P. J. GRAHAM; D. HENDERSON; N. J. L. L. PEDERSEN. The Routledge Handboook of Social Epistemology. Routledge, p. 40-48, 2020.

RECEIVED: 02/05/2020

APPROVED: 06/14/2020

RECEBIDO: 05/02/2020

APROVADO: $14 / 06 / 2020$ 